\title{
Association of the DNMT3A -448A>G polymorphism with genetic susceptibility to colorectal cancer
}

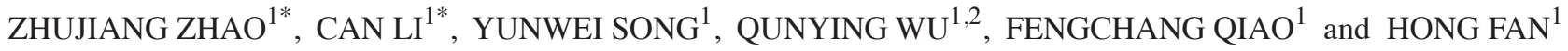 \\ ${ }^{1}$ Department of Genetics and Development, Southeast University Medical School, and Key Laboratory \\ of Developmental Genes and Human Diseases, Ministry of Education, Southeast University, \\ Nanjing 210009; ${ }^{2}$ Institute of Biotechnology, Guilin Medical University, Guilin 541004, P.R. China
}

Received June 21, 2011; Accepted September 29, 2011

DOI: $10.3892 / \mathrm{ol} .2011 .488$

\begin{abstract}
The DNA methyltransferase 3A (DNMT3A) $-448 \mathrm{~A}>\mathrm{G}$ polymorphism is a novel functional single nucleotide polymorphism (SNP) that contributes to the genetic susceptibility to gastric cancer. In this study, we aimed to assess the genotype frequencies of DNMT3A $-448 \mathrm{~A}>\mathrm{G}$ in colorectal cancer $(\mathrm{CRC})$ patients and healthy control subjects, and to explore the association of the DNMT3A functional SNP, $-448 \mathrm{~A}>\mathrm{G}$, with genetic susceptibility to CRC. Genomic DNA was extracted from samples of 258 patients with CRC and 280 healthy controls. Polymerase chain reaction-restriction fragment length polymorphism analysis was employed to assess the genotype frequencies of DNMT3A -448A $>\mathrm{G}$ in all of the subjects. Stratification analyses were used to study subgroups of subjects by age and gender, and to evaluate the association between the DNMT3A $-448 \mathrm{~A}>\mathrm{G}$ polymorphism and the genetic susceptibility to $\mathrm{CRC}$. The allele frequency of -448A among CRC patients and the controls was 26.4 versus $19.8 \%$, respectively. Overall, we found that compared with GG carriers, the DNMT3A -448AA homozygotes had a 3.692-fold increased risk of CRC. Stratification analysis showed a significant difference in this SNP between the CRC patients and the control subjects of different genders. AA homozygotes carried an increased risk in the subgroup of individuals aged $\geq 50$ years in male CRC. Compared with GG homozygotes in females aged $\geq 50$ years, the AG and AA genotypes carried a 0.355 -fold decreased risk in this subgroup. These data imply that the DNMT3A SNP -448A $>$ G contributes to genetic susceptibility to $\mathrm{CRC}$. $-448 \mathrm{~A}>\mathrm{G}$ may be used as a stratification marker to
\end{abstract}

Correspondence to: Dr Hong Fan, Department of Genetics and Development, Southeast University Medical School, Dingjiaqiao 87, Nanjing, Jiangsu 210009, P.R. China

E-mail: fanh@seu.edu.cn

*Contributed equally

Key words: colorectal cancer, DNA methyltransferase 3A, single nucleotide polymorphism $-448 \mathrm{~A}>\mathrm{G}$, polymerase chain reaction-restriction fragment length polymorphism predict the susceptibility of certain individuals to CRC, particularly in male individuals aged $\geq 50$ years.

\section{Introduction}

Colorectal cancer (CRC) is the leading cause of cancer-related mortality for males and females worldwide (1). Although significant progress has been made to understand the genetic changes associated with cancer, there are few useful biomarkers for identifying individuals at high risk in the general population. DNA methyltransferase 3A (DNMT3A) plays a significant part in the development of embryogenesis and in the generation of aberrant methylation in carcinogenesis (2). The expression of DNMT3A is increased in parallel to the degree of dysplasia, with significant overexpression in the malignant lesion when compared with normal mucosa (3). Elevated Dnmt3a activity promotes polyposis in Apc(Min) mice by relaxing the extracellular restraints on Wnt signaling (4). Our previous study found a novel DNMT3A functional single nucleotide polymorphism (SNP), -448A $>\mathrm{G}$, and showed that a DNMT3A promoter genetic variant increased its transcriptional activity and contributed to the genetic susceptibility to gastric cancer (GC) in the Chinese population (5). However, an association between the DNMT3A -448A $>$ G polymorphism and CRC has not been reported as yet. In this case-control study, we genotyped this DNMT3A polymorphism and investigated the association between the $-448 \mathrm{~A}>\mathrm{G}$ functional $\mathrm{SNP}$ and $\mathrm{CRC}$.

\section{Materials and methods}

Study subjects. CRC patients were selected consecutively from the Zhongda Hospital of Southeast University and Jiangsu Tumor Hospital, China. The 258 case subjects were diagnosed and CRC was histopathologically confirmed. The 280 healthy controls were selected from cancer-free individuals at the same hospital and were frequency-matched to the case patients based on age, gender and ethnicity. All of the subjects were ethnically Chinese and resided in the Jiangsu Province of China or the surrounding area. All samples were obtained with informed consent from the subjects and the approval of the Institutional Review Board at the Zhongda Hospital of Southeast University and Jiangsu Tumor Hospital in Jiangsu province, from September 2006 to February 2011. 
The controls were cancer-free individuals who visited the same hospital for routine physical examinations or who had volunteered to participate in the epidemiology survey during the same period.

DNMT3A genotyping. Total genomic DNA was isolated from 258 patients with CRC and 280 healthy controls by proteinase $\mathrm{K}$ digestion (6). As the transition of $\mathrm{A}>\mathrm{G}$ of the DNMT3A SNP creates a TaaI restriction site, polymerase chain reaction-restriction fragment length polymorphism (PCR-RFLP) analysis was used to detect this A-G transition in the promoter of DNMT3A at $-448 \mathrm{~A}>\mathrm{G}$ (GenBank accession no. NT_022184.15:g.4387794AG). The DNMT3A -448A>G polymorphism was determined using a PCR-RFLP assay. The PCR reaction was performed in a total volume of $25 \mu 1$, containing $100 \mathrm{ng}$ genomic DNA, $0.1 \mathrm{mM}$ dNTPs, $2.0 \mathrm{mM}$ $\mathrm{MgCl}_{2}, 10 \mu \mathrm{M}$ primers 5'-ACACACCGCCCTCACCCCTT-3' (forward), and 5'-TCCAGCAATCCCTGCCCACA-3' (reverse), and 1.25 U Taq polymerase (Biocolor BioScience and Technology Company, Shanghai, China). PCR cycle conditions included an initial melting step of $95^{\circ} \mathrm{C}$ for $5 \mathrm{~min}$, followed by 32 cycles of $95^{\circ} \mathrm{C}$ for $20 \mathrm{sec}, 68^{\circ} \mathrm{C}$ for $20 \mathrm{sec}$ and $72^{\circ} \mathrm{C}$ for $30 \mathrm{sec}$, and a final extension step of $72^{\circ} \mathrm{C}$ for $5 \mathrm{~min}$. The 358 bp fragment was then digested with TaaI (Fermentas Co., Glen Burnie, MD, USA) for $5 \mathrm{~min}$ at $65^{\circ} \mathrm{C}$, the digested products were then separated on a $3.0 \%$ agarose gel, and the RFLP bands were visualized under UV light with ethidium bromide (EB) staining. The wild-type $\mathrm{G}$ allele had a TaaI restriction site that resulted in three bands (153,94 and $87 \mathrm{bp})$, while the variant A allele resulted in four bands (247, 153, 94 and $87 \mathrm{bp}$ ).

Statistical analysis. SPSS 13.0 software (SPSS Inc., Chicago, IL, USA) was used to perform all statistical comparisons. All comparisons were two-tailed, and $\mathrm{P}<0.05$ was considered to be statistically significant. DNMT3A genotype and allele distributions among the study groups were calculated with odds ratios (ORs) and 95\% confidence intervals (CIs) by means of two-sided contingency tables using the $\chi^{2}$ test. Stratification analysis was used to study subgroups of subjects by age and gender.
Table I. Characteristics of the study population.

\begin{tabular}{lcrc}
\hline Variables & $\begin{array}{c}\text { CRC cases } \\
(\mathrm{n}=258)\end{array}$ & $\begin{array}{c}\text { Controls } \\
(\mathrm{n}=280)\end{array}$ & P-value $^{\mathrm{b}}$ \\
\hline $\begin{array}{l}\text { Age (years }) \\
<50\end{array}$ & $58(22.5)^{\mathrm{a}}$ & $46(16.4)$ & 0.076 \\
$\geq 50$ & $200(77.5)$ & $234(83.6)$ & \\
Gender & & & 0.153 \\
Male & $158(61.2)$ & $188(67.1)$ & \\
Female & $100(38.8)$ & $92(32.9)$ & \\
& & &
\end{tabular}

${ }^{\mathrm{a}}$ Numbers in parentheses, percentage; ${ }^{\mathrm{b}} \mathrm{P}$-values for Chi-square $\left(\chi^{2}\right)$ test. $\mathrm{CRC}$, colorectal cancer.

\section{Results}

The DNMT3A genotypes, AA, AG and GG, were detected in the $\mathrm{CRC}$ patients and the controls. There were no significant differences in the distribution of the mean age and gender between the cases and the controls, suggesting that the matching based on these two variables was satisfactory (Table I). The genotyping by PCR-RFLP analysis was confirmed by DNA sequencing analysis. All of the cases and controls were successfully genotyped for the DNMT3A polymorphism. The distributions of $-448 \mathrm{~A}>\mathrm{G}$ genotypes in the 280 control subjects were $\mathrm{GG}$ $63.6 \%$, GA $33.2 \%$ and AA $3.2 \%$, and the A allele frequency was $19.8 \%$, while the $-448 \mathrm{~A}$ allele frequency was $26.4 \%$ in CRC (Table II). There are significantly different frequencies of $-448 \mathrm{~A}>\mathrm{G}$ between the male and female patients in CRC (Table III). The $-448 \mathrm{~A}>\mathrm{G}$ polymorphism of the DNMT3A promoter evaluated the risk related to $\mathrm{CRC}$ groups in the casecontrol study. The CRC risk related to the DNMT3A -448A $>\mathrm{G}$ genotype is shown in Table IV. The distributions of $-448 \mathrm{~A}>\mathrm{G}$ genotypes in the CRC group (GG 58.1\%, AG 31.0\% and AA $10.9 \%$ ) were significantly different from those among the controls (GG 63.6\%, GA 33.2\% and AA 3.2\%). As compared with the reference group -448GG genotypes, AA homozygotes carried a 3.692-fold increased risk of CRC $(\mathrm{P}=0.001)$.

Table II. DNMT3A -448A>G genotype and allele frequencies of colorectal cancer cases and control.

\begin{tabular}{|c|c|c|c|c|c|c|}
\hline \multirow[t]{2}{*}{ Genotype } & \multicolumn{2}{|c|}{$\begin{array}{l}\text { Colorectal cancer } \\
\qquad(\mathrm{n}=258)\end{array}$} & \multicolumn{2}{|c|}{$\begin{array}{l}\text { Control subjects } \\
\qquad(n=280)\end{array}$} & \multirow[t]{2}{*}{$\begin{array}{l}\text { Crude OR } \\
(95 \% \mathrm{CI})\end{array}$} & \multirow[t]{2}{*}{ P-value } \\
\hline & No. & $(\%)$ & No. & $(\%)$ & & \\
\hline \multicolumn{7}{|l|}{$-448 \mathrm{~A}>\mathrm{G}$} \\
\hline GG (ref.) & 150.0 & 58.1 & 178 & 63.6 & 1 & \\
\hline AG & 80.0 & 31.0 & 93 & 33.2 & $1.021(0.705-1.477)$ & 0.913 \\
\hline AA & 28.0 & 10.9 & 9 & 3.2 & $3.692(1.689-8.068)$ & 0.001 \\
\hline $\mathrm{AG}+\mathrm{AA}$ & 108.0 & 41.9 & 102 & 36.4 & $1.256(0.888-1.778)$ & 0.197 \\
\hline A allele & 26.4 & 19.8 & & & & \\
\hline
\end{tabular}

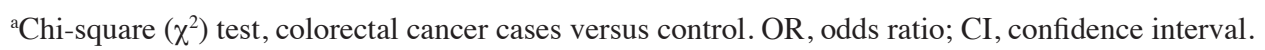


Table III. DNMT3A -448A >G genotype and allele frequencies in colorectal cancer cases.

\begin{tabular}{|c|c|c|c|c|c|}
\hline \multirow[t]{2}{*}{ Groups } & \multicolumn{3}{|c|}{ Genotype } & \multicolumn{2}{|c|}{ Allele } \\
\hline & $\mathrm{GG}(\%)$ & $\mathrm{AG}(\%)$ & $\mathrm{AA}(\%)$ & $\mathrm{A}(\%)$ & P-value ${ }^{a}$ \\
\hline Total & $150(58.1)$ & $80(31.0)$ & 28 (10.9) & 26.4 & \\
\hline Age (years) & & & & & $0.710^{\mathrm{b}}$ \\
\hline$<50$ & $33(12.8)$ & 17 (6.6) & $8(3.1)$ & 28.4 & \\
\hline$\geq 50$ & $117(45.3)$ & $63(24.4)$ & $20(7.8)$ & 25.8 & \\
\hline Gender & & & & & $0.015^{\mathrm{c}}$ \\
\hline Male & 103 (39.9) & $40(15.5)$ & $15(5.8)$ & 22.2 & \\
\hline Female & 47 (18.2) & $40(15.5)$ & $13(5.1)$ & 33.0 & \\
\hline
\end{tabular}

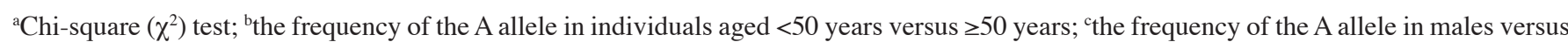
females.

Table IV. Distribution of $-448 \mathrm{~A}>\mathrm{G}$ DNMT3A genotypes and the associated odds ratios (ORs) in relation to age and gender in CRC cases.

\begin{tabular}{|c|c|c|c|c|}
\hline Genotype & Controls (\%) & CRC cases $(\%)$ & OR & P-value ${ }^{a}$ \\
\hline \multicolumn{5}{|l|}{ Male } \\
\hline GG & $151(54.0)$ & $103(39.9)$ & 1 & \\
\hline $\mathrm{AG}$ & $33(11.8)$ & $40(15.5)$ & $1.777(1.052-3.003)$ & 0.031 \\
\hline AA & $4(1.4)$ & $15(5.8)$ & $5.498(1.774-17.036)$ & 0.001 \\
\hline $\mathrm{AA}+\mathrm{AG}$ & $37(13.2)$ & $55(21.3)$ & $2.179(1.340-3.544)$ & 0.002 \\
\hline \multicolumn{5}{|c|}{ Male $<50$ yrs } \\
\hline GG & $14(5.0)$ & $19(7.3)$ & 1 & \\
\hline $\mathrm{AG}$ & $14(5.0)$ & $9(3.5)$ & $0.474(0.160-1.402)$ & 0.174 \\
\hline AA & $1(0.3)$ & $3(1.1)$ & $2.211(0.207-23.555)$ & 0.503 \\
\hline $\mathrm{AA}+\mathrm{AG}$ & $15(5.3)$ & $12(4.6)$ & $0.589(0.211-1.645)$ & 0.311 \\
\hline \multicolumn{5}{|c|}{ Male $\geq 50$ yrs } \\
\hline GG & $137(49.0)$ & $84(32.6)$ & 1 & \\
\hline $\mathrm{AG}$ & $19(6.8)$ & $31(12.0)$ & $2.661(1.414-5.008)$ & 0.002 \\
\hline AA & $3(1.1)$ & $12(4.7)$ & $6.524(1.789-23.794)$ & 0.001 \\
\hline $\mathrm{AA}+\mathrm{AG}$ & $22(7.9)$ & $43(16.7)$ & $3.188(1.783-5.700)$ & 0.000 \\
\hline \multicolumn{5}{|l|}{ Female } \\
\hline GG & $27(9.6)$ & $47(18.2)$ & 1 & \\
\hline $\mathrm{AG}$ & $60(21.4)$ & $40(15.5)$ & $0.383(0.206-0.712)$ & 0.002 \\
\hline AA & $5(1.8)$ & $13(5.1)$ & $1.494(0.480-4.646)$ & 0.487 \\
\hline $\mathrm{AA}+\mathrm{AG}$ & $65(23.2)$ & $53(20.6)$ & $0.468(0.258-0.850)$ & 0.012 \\
\hline \multicolumn{5}{|c|}{ Female $<50$ yrs } \\
\hline GG & $10(3.6)$ & $14(5.4)$ & 1 & \\
\hline AG & $7(2.5)$ & $8(3.1)$ & $0.816(0.223-2.992)$ & 0.759 \\
\hline AA & $0(0.0)$ & $5(2.0)$ & $-{ }^{b}$ & 0.134 \\
\hline $\mathrm{AA}+\mathrm{AG}$ & $7(2.5)$ & $13(5.1)$ & $1.327(0.389-4.520)$ & 0.651 \\
\hline \multicolumn{5}{|c|}{ Female $\geq 50$ yrs } \\
\hline GG & $17(6.0)$ & $33(12.8)$ & 1 & \\
\hline $\mathrm{AG}$ & $53(18.9)$ & $32(12.4)$ & $0.311(0.150-0.646)$ & 0.001 \\
\hline AA & $5(1.8)$ & $8(3.1)$ & $0.824(0.233-2.910)$ & 0.755 \\
\hline $\mathrm{AA}+\mathrm{AG}$ & $58(20.7)$ & $40(15.5)$ & $0.355(0.175-0.723)$ & 0.004 \\
\hline
\end{tabular}

${ }^{a}$ Chi-square $\left(\chi^{2}\right)$ test, CRC cases versus control. ${ }^{b}$ No significance as the frequency of the AA genotype in this subgroup of CRC is zero. CRC, colorectal cancer. 
When the analyses were stratified by the age and gender of the patients, the -448AA genotype was associated with the genetic susceptibility to CRC in males, particularly in individuals older than 50 years of age (OR, 6.524; 95\% CI, 1.789-23.794; $\mathrm{P}=0.001)$. Individuals who carried at least one A allele (AG or AA) had a 2.179-fold increased OR of developing CRC compared to those who carried the GG wild-type genotype (95\% CI, 1.340-3.544; $\mathrm{P}=0.002)$. The risk associated with the combined $\mathrm{AA}+\mathrm{AG}$ genotypes was more pronounced in older subjects, and in males rather than females. There was a significant difference in the frequency of AG heterozygotes $(\mathrm{P}=0.002)$ between the cases and controls among females. Individuals who carried at least one A allele (AG or AA) had a 0.468-fold decreased OR of developing CRC compared to those who carried the GG wild-type genotype (95\% CI, $0.258-0.850 ; \mathrm{P}=0.012)$. In particular, $\mathrm{AG}$ heterozygotes had a greater reduced risk of developing $\mathrm{CRC}$ in females older than 50 years (OR, $0.311 ; 95 \%$ CI, $0.150-0.646 ; \mathrm{P}=0.001)$.

\section{Discussion}

CRC is one of the main causes of cancer mortality worldwide. A series of studies have suggested that there is aberrant DNA methylation in colorectal carcinoma cells, including inactivation and $\mathrm{CpG}$ island hypermethylation of certain tumor-suppressor genes, including CD133 (7), MLHI, MGMT (8),APC, MGMT, RASSF2A and Wif-1 (1). Given that the HIF-1 $\alpha$ SNPC1772T (9), the DNA repair gene XRCC3 (10) SNP and the E-cadherin gene SNP -347 G $\rightarrow$ GA (11) and -160 $\mathrm{C} \rightarrow \mathrm{A}(12)$ are associated with the genetic susceptibility to CRC, DNMT3A is responsible for DNA methylation as a de novo methyltransferase in the tumorigenesis of numerous types of cancer, including CRC. Previous studies have suggested that ectopic DNMT3A expression plays a significant role in CRC progression $(13,14)$. The restriction of Dnmt3a overexpression showed hypermethylation-mediated transcriptional silencing of the Wnt antagonist Sfrp5, and to a lesser extent, Sfrp1 (4). Our previous study showed a novel functional polymorphism, $-448 \mathrm{~A}>\mathrm{G}$, in the promoter of the DNMT3A gene, and this polymorphism was associated with the risk of cancer, particularly with GC. To the best of our knowledge, the correlation between the DNMT3A polymorphism and the risk of CRC has not been reported as yet. We hypothesized that this functional DNMT3A -448A $>$ G polymorphism is associated with genetic susceptibility to CRC. Stratification analyses showed that there was a significant difference in the frequency of $A G$ heterozygotes and AA homozygotes in CRC.

According to our analysis of the DNMT3A gene promoter $-448 \mathrm{~A}>\mathrm{G}$ polymorphism among a Chinese CRC and control group, we found that the A variant genotype was associated with a significantly increased risk of CRC. The AA genotype was associated with a significantly increased risk of CRC in males aged $\geq 50$ years. The data provide crucial evidence that -448A carries a significant likelihood of carcinogenesis for older male CRC patients, at least in this Chinese population. This functional polymorphism modifies the susceptibility to $\mathrm{CRC}$, and may be a risk predictor for male CRC, particularly in the group aged $\geq 50$ years. In addition to this, another significant finding is that the females carrying the $-448 \mathrm{AA}$ genotype had a decreased risk of CRC, suggesting that this polymorphism may be a protective factor for CRC in females of Chinese origin. Research has shown that the risk of CRC varies in different genders, ethnicities and ages $(11,15,16)$. The mechanism for this should be investigated in further studies, as there is not enough evidence to explain it at the present. Moreover, further studies are required to confirm our findings with larger sample sizes and in more populations. In the present study, we can only highlight this significant result and make the hypothesis that the DNMT3A -448A $>$ G polymorphism is associated with the risk of $\mathrm{CRC}$ and relates to gender and age. Given that the size of the samples in the subgroups was not large enough to draw any conclusion, further studies are required.

\section{Acknowledgements}

This study was supported by the Qinglan project of Jiangsu Province in China. We thank Dr Jinfei Chen, Dr Wang Weiwen, Dr Zhou Xiaoyue and Dr Gu Hongbing for their assistance in the collection of blood samples. We also thank Dr Hui Jin for verifying the data by statistical analysis.

\section{References}

1. Lee BB, Lee EJ, Jung EH, Chun HK, Chang DK, Song SY, Park J and Kim DH: Aberrant methylation of APC, MGMT, RASSF2A, and Wif-1 genes in plasma as a biomarker for early detection of colorectal cancer. Clin Cancer Res 15: 6185-6191, 2009.

2. Robertson KD, Uzvolgyi E, Liang G, Talmadge C, Sumegi J, Gonzales FA and Jones PA: The human DNA methyltransferases (DNMTs) 1, 3a and 3b: coordinate mRNA expression in normal tissues and overexpression in tumors. Nucleic Acids Res 27: 2291-2298, 1999.

3. Schmidt WM, Sedivy R, Forstner B, Steger GG, Zochbauer-Muller S and Mader RM: Progressive up-regulation of genes encoding DNA methyltransferases in the colorectal adenoma-carcinoma sequence. Mol Carcinog 46: 766-772, 2007.

4. Samuel MS, Suzuki H, Buchert M, Putoczki TL, Tebbutt NC, Lundgren-May T, Christou A, Inglese M, Toyota M and Heath JK: Elevated Dnmt3a activity promotes polyposis in Apc(Min) mice by relaxing extracellular restraints on Wnt signaling. Gastroenterology 137: 902-913, 2009.

5. Fan H, Liu D, Qiu X, Qiao F, Wu Q, Su X, Zhang F, Song Y, Zhao $\mathrm{Z}$ and Xie W: A functional polymorphism in the DNA methyltransferase-3A promoter modifies the susceptibility in gastric cancer but not in esophageal carcinoma. BMC Med 8: 12, 2010.

6. Fan H, Liu DS, Zhang SH, Hu JB, Zhang F and Zhao ZJ: DNMT3B $579 \mathrm{G}>\mathrm{T}$ promoter polymorphism and risk of esophagus carcinoma in Chinese. World J Gastroenterol 14: 2230-2234, 2008.

7. Yi JM, Tsai HC, Glockner SC, Lin S, Ohm JE, Easwaran H, James CD, Costello JF, Riggins G and Eberhart CG: Abnormal DNA methylation of CD133 in colorectal and glioblastoma tumors. Cancer Res 68: 8094-8103, 2008.

8. Jass JR: Serrated adenoma of the colorectum and the DNA-methylator phenotype. Nat Clin Pract Oncol 2: 398-405, 2005.

9. Kuwai T, Kitadai Y, Tanaka S, Kuroda T, Ochiumi T, Matsumura S, Oue N, Yasui W, Kaneyasu M and Tanimoto K: Single nucleotide polymorphism in the hypoxia-inducible factor- $1 \alpha$ gene in colorectal carcinoma. Oncol Rep 12: 1033-1037, 2004.

10. Mort R, Mo L, McEwan C and Melton DW: Lack of involvement of nucleotide excision repair gene polymorphisms in colorectal cancer. Br J Cancer 89: 333-337, 2003.

11. Shin Y, Kim IJ, Kang HC, Park JH, Park HW, Jang SG, Lee MR, Jeong SY, Chang $\mathrm{HJ}$ and Ku JL: A functional polymorphism $(-347 \mathrm{G}-->\mathrm{GA})$ in the E-cadherin gene is associated with colorectal cancer. Carcinogenesis 25: 2173-2176, 2004.

12. Shan K, Xiao-Wei M, Na W, Xiu-Feng Z, Deng-Gui W, Wei G, Zheng-Mao Z and Yan L: Association of three single nucleotide polymorphisms of the E-cadherin gene with endometriosis in a Chinese population. Reproduction 134: 373-378, 2007. 
13. Schneider-Stock R, Diab-Assef M, Rohrbeck A, Foltzer-Jourdainne C, Boltze C, Hartig R, Schonfeld P, Roessner A and Gali-Muhtasib H: 5-Aza-cytidine is a potent inhibitor of DNA methyltransferase $3 \mathrm{a}$ and induces apoptosis in HCT-116 colon cancer cells via Gadd45- and p53-dependent mechanisms. J Pharmacol Exp Ther 312: 525-536, 2005.

14. Nelson RL, Dollear T, Freels S and Persky V: The relation of age, race, and gender to the subsite location of colorectal carcinoma. Cancer 80: 193-197, 1997.
15. Troisi RJ, Freedman AN and Devesa SS: Incidence of colorectal carcinoma in the U.S.: an update of trends by gender, race, age, subsite, and stage, 1975-1994. Cancer 85: 1670-1676, 1999.

16. Anderson WF, Umar A and Brawley OW: Colorectal carcinoma in black and white race. Cancer Metastasis Rev 22: 67-82, 2003. 